\title{
P-143
}

\section{Antibacterial and Antioxidant Activities from the Extracts of the Leaves of Phoebe Grandis (Nees) Merr}

\author{
Hanita Omar ${ }^{1,2, *}$, Noor Shafifiyaz Mohd Yazid ${ }^{3}$, Asdren Zajmi ${ }^{3}$, Najihah Mohd. Hashim ${ }^{3}$ and \\ A. Hamid A. Hadi ${ }^{1}$ \\ ${ }^{1}$ Chemistry Department, Faculty of Science, University of Malaya,50603, Kuala Lumpur,Malaysia; ${ }^{2}$ Centre for \\ Foundation Studies in Sciences, University of Malaya,50603, Kuala Lumpur, Malaysia; ${ }^{3}$ Department of Pharmacy, \\ Faculty of Medicine, University of Malaya, 50603 Kuala Lumpur, Malaysia; E-mail: hanita74@um.edu.my
}

The genus of Phoebe of family Lauraceae is found the most abundance in Borneo and the Malaysian Peninsular. Phoebe grandis locally known as 'medang ketanah or tanah.' The isolation of three compounds lysicamine (1), N-methyllitsericinone (2), N-methyllitsericine (3) were evaluated against selected pathogenic bacteria which are Staphylococcus epidermidis, Staphylococcus aureus, Bacillus, Pasteurella multocida and Enterobacter cloacae. Lysicamine (1) showed strong antibacterial activity against all bacteria strains. (The result will be highlighted during the presentation). Meanwhile, the biological screening of antioxidant activities were determined using DPPH scavenging and ferric reducing antioxidant power (FRAP) assays. The present study of the hexane, dichloromethane, methanol and alkaloid extracts from the leaves of Phoebe grandis showed these extracts had good scavenging activity. The antioxidant activity gave potent result to the alkaloids extract compared to other extracts.

Keywords: Antibacterial activity, Antioxidant activity, Phoebe grandis, alkaloids, lysicamine. 